\title{
معوقات تطبيق مهارات التفكير الأساسية في تدريس مادة التربية الاسلامية من وجهة نظر المدرسين للمرحلة الثانوية في مدينة بغداد
}

م م د وليد عبد الرحمن إسماعيل العبيدي

كلية التربية / جامعة واسط السماعل العبائ

\section{ملخص البحث}

أتفق المختصين والمربين على ضرورة تعلم التفكير وتطوير المهارات التفكيرية لاى الطلبة جميعهم ، وعلى

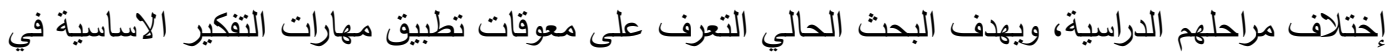

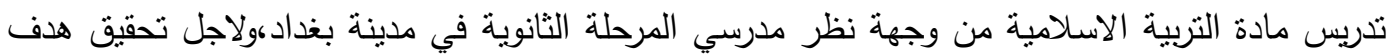

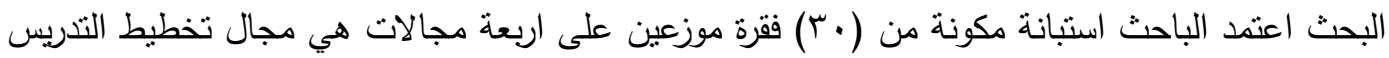

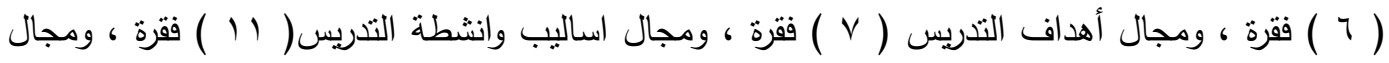

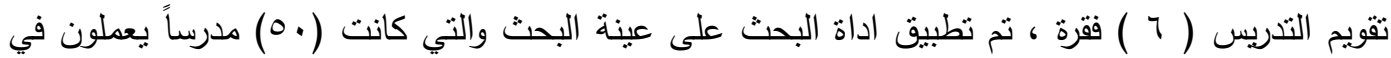

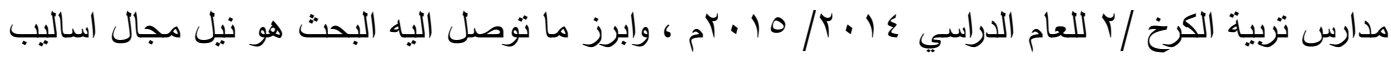

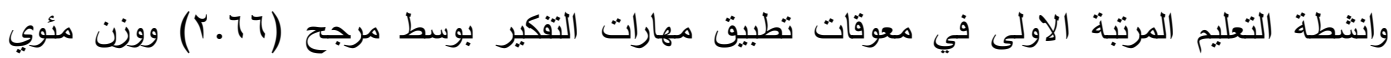

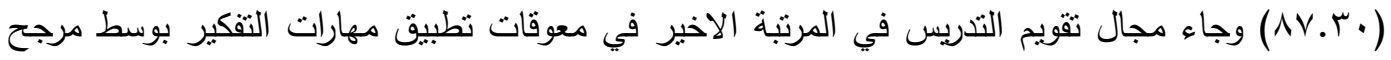

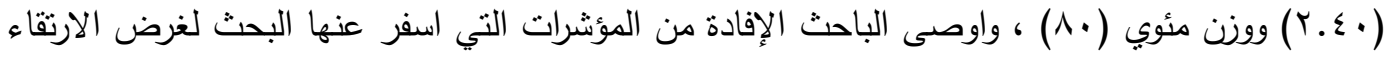

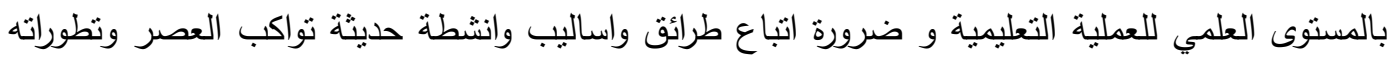
وتنتمي لاى الطلبة مهارات التفكير. 


\begin{abstract}
It was agreed that specialists and educators need to learn thinking and develop thinking skills among all students at different school levels and current research aims to identify the obstacles to application of thinking skills in teaching lslamic education from the viewpoint of secondary school teachers in the city of Baghdad in order to achieve the objective of the research the researcher adopted a questionnaire consisting of (30) spread over four areas of teaching planning(6) and field goals (7) and teaching methods and activities (11) and field teaching calendar (6) paragraph applied tool research on sample search (50) teachers work in Karkh farming/ 2 to 2014/2015 academic year and highlighted the findings of the research is attainment methods rank first in constraints apply thinking skills central casting (2.66) and centenary (87.30) teaching calendar field came in ranked last in the constraints apply thinking skills central casting (2.40) and centenary (80) and the researcher recommended that benefit from the research indicators for the purpose of raising the scientific level of the educational process and the need to follow the procedure and the working methods and activities outdated and modern developments and develop students" thinking skills
\end{abstract}


تعليم مهارات التفكير حركة قديمة ومعاصرة ، وهي تمثل اليوم إتجاهاً حيوياً مثيراً لدى التزبوبين ،

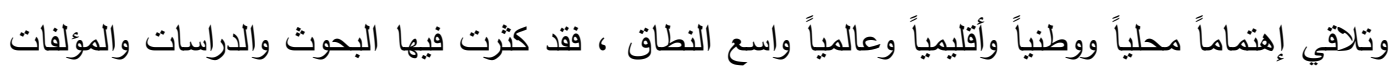

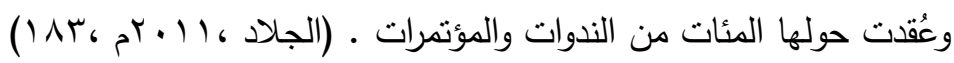

وقد ثبت من خلال تلك الدراسات والمؤتمرات والندوات أن مهارات التفكير لا تتمو تلقائياً لاى المتعلم من خلال تدريسه المواد الدراسية بالطرائق التقليدية ، بل لعل هذا التدريس يكون عائقاً في نمو

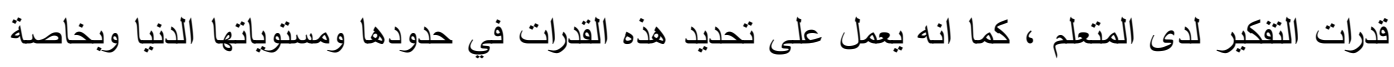

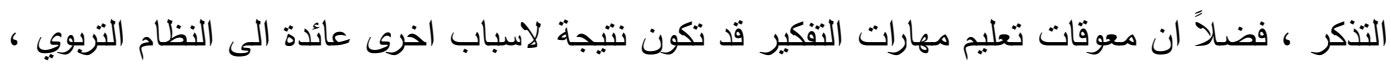

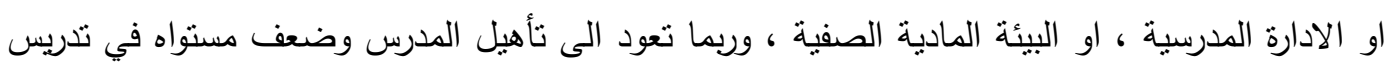

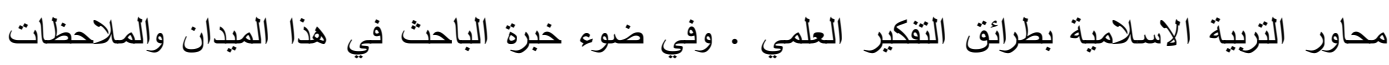

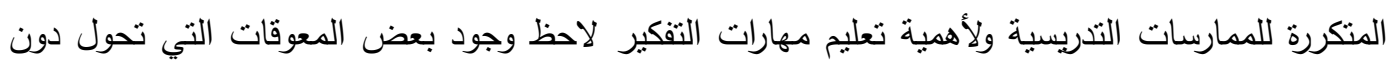
تطبيق هذا النوع من التدريس في مادة التربية الاسلامية ، لذلك تحددت مشكلة البحث بالسؤال الرئيس الاتي لأي

( ما معوقات نطبيق مهارات التفكير الأساسية في تدريس مادة التربية الاسلامية من وجهة نظر

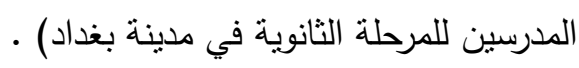

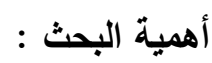

يعد التفكير هبة وعنوان تكريم خص اله به الإنسان ، إذ منحه قدرة التفكر والتآمل والبحث

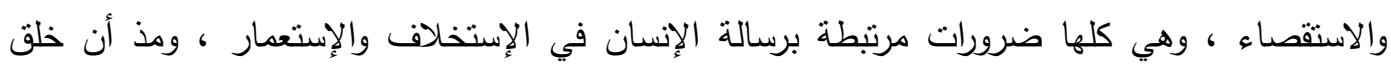
الإنسان وحمل الأمانة الكبرى وهب معها ملكات مميزة له عن سائر المخلوقات فحواها الإرادة الفاعلة القائمة 
على حرية الاختبار المستتبطة من قدرته على التقكير والاختبار من بين البدائل وأتخاذ القرارات وحل

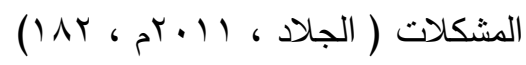

وحث القرآن الكريم على تربية العقل ودعوته للتآمل والتفكير والنظر والإعتبار ، فنللك آيات القرآن الكريم

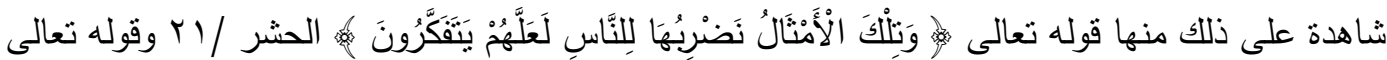

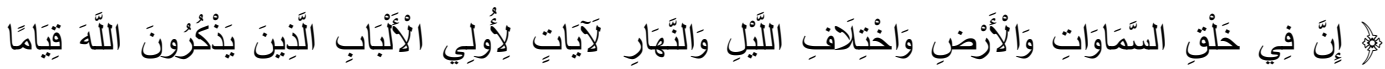

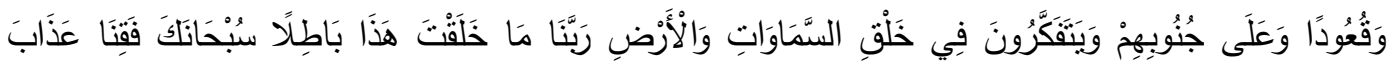

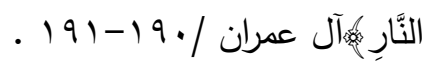

لذلك أتفق المختصين والمربين على ضرورة نعلم التفكير وتطوير المهارات التفكيرية لاى جميع الطلبة ، وعلى إختلاف مراحلهم الدراسية وتتأكد هذه الضرورة بأمرين هما : عد التفكير مهارة وأي مهارة تحتاج في إكتسابها إلى التعليم ، وان التفكير عملية معقدة متعددة الجوانب تتأثر بعوامل كثيرة وتقف في طريقها

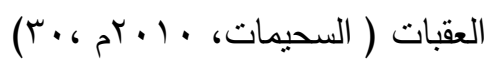

ومن أهم اسباب نجاح تعليم التفكير وجود مدرس فعال يمارس مهارات التفكير داخل الغرفة الصفية في عملية التدريس إذ ينبغي على المدرس الابتعاد عن طرائق التدريس التقليدية التي تقوم على التلقين ، وتزويد الطلبة بالمعلومات دون نتمية تفكيرهم ، بالإضافة إلى تجثيعهم على التعلم النشط وحثهم على ممارسة

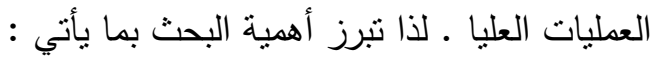

1- نستمد أهمية البحث من أهمية موضوعه وحداثته إذ تتثير معظم التوصيات في الدراسات السابقة إلى ضرورة تطبيق مهارات التفكير في تدريس المواد الدراسية . ז- قلة الدارسات السابقة في معوقات تطبيق مهارات التفكير في تدريس التربية الاسلامية حسب علم

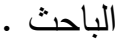

r- إفادة مدرسي التربية الاسلامية للمرحلة الثانوية في التعرف على المعوقات التي نواجههم في تدريس مادة التربية الاسلامية في ضوء مهارات التفكير الأساسية . 
يهدف البحث الحالي التعرف على معوقات تطبيق مهارات التفكير الأساسية في تدريس مادة التربية الاسلامية من وجهة نظر مدرسي المرحلة الثانوية في مدينة بغداد .

تم تطبيق البحث الحالي على مدرسي ومدرسات المرحلة الثانوية لمادة التربية الاسلامية في المدارس (

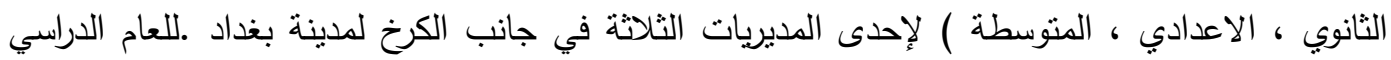
r.1T/ T.10

\section{تحديد المصطلحات :}

اولاً : معوقات : لغةًً العائق في لسات العرب يعاقه عن الثيء يعوقه : صرفه وحبسه ، والتعويق معناه إذا

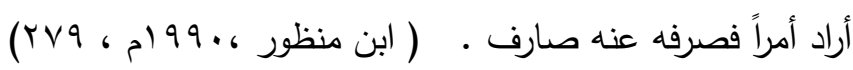

اما إصطلاحاً عرفها الفارابي وزملاؤه في معجم علوم التربية العائق بأنه صعوبة يصادفها المتعلم خلال

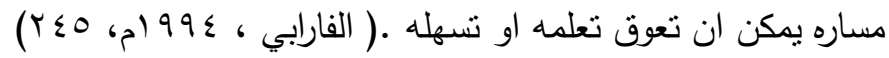

اما التعريف الإجرائي يعرفها الباحث بإنها مجموعة صعوبات تؤثر على عملية تطبيق مهارات التفكير في تدريس مادة التربية الاسلامية في المرحلة الثانوية .

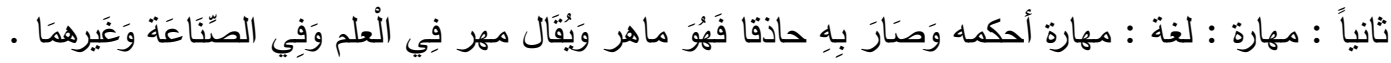

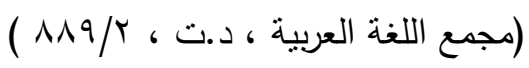

المهارة اصطلاحاً هي التمكن من إنجاز مهمة بكيفية محدودة وبدقة متتاهية وسرعة في التفيذ من خلال

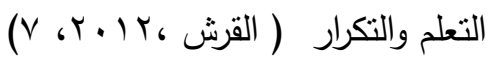


اما التعريف الإجرائي هي اتقان المدرس لمجموعة مهارات التقكير الأساسية في تدريسه لمادة التربية

الاسلامية في المرحلة الثانوية . لإنيا

ثالثاً: التفكير :

لغةً : الفكر هو : إعمال الخاطر في الثيء، وجمعه أفكار والفكرة كالفكر ، وفكر في الثيء وافكر فيه

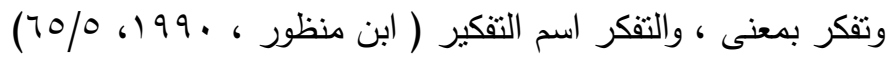

اما التفكير إصطلاحاً: مهارة ذهنية كلية يتم عن طريقها معالجات ذهنية للمدخلات الحسية والمعلومات المسترجعة لتكوين الافكار أو معالجتها أو الحكم عليها ، وتتضمن الإدراك والخبرة السابقة والمعالجة الواعية

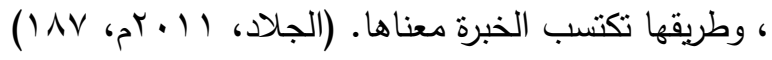

مهارات التفكير : معالجات ذهنية تمارس وتستخدم عن قصد في التفاعل مع المعلومات او المواقف ،

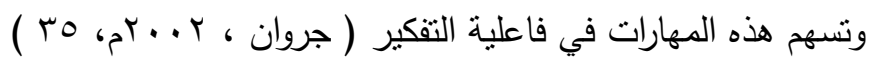

اما التعريف الإجرائي فهي تتمنل في اثهر المهارات الأساسية العامة في التفكير والتي تتضمن المقارنة ، التصنيف ، التتظيم ، التعميم ، التحليل ، التركيب ، الاستتباط ، الاستقراء .

$$
\text { رابعاً: التدريس: }
$$

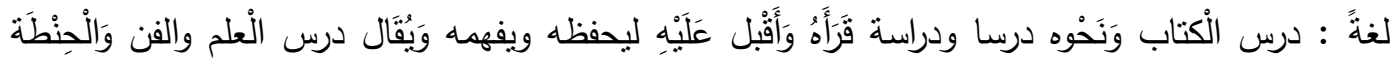

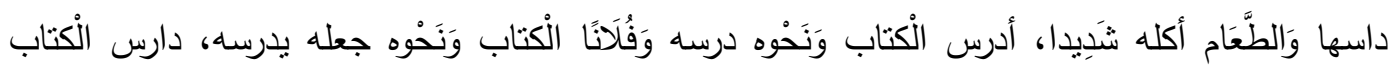

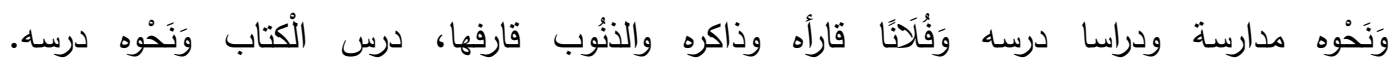

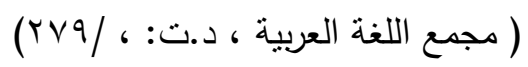

اصطلاحاً: هو عملية إجتماعية تتكون من مجموعة من الإنشطة والاجراءات التي يتم من خلالها نقل مادة

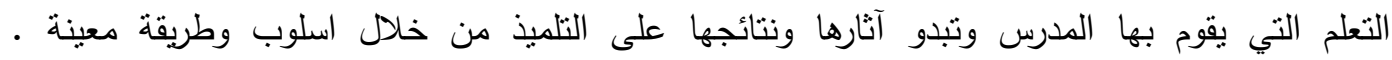

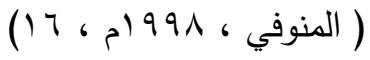


وعرفه موسى بانه عملية متعدة لنتكيل بيئة الفرد بصورة تمكنه من أن يتعلم القيام بسلوك محدد او الاثتراك في سلوك معين نحت شروط محددة او كاستجابة لظروف محدد

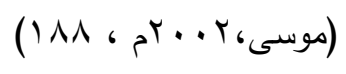

الام التعريف الاجرائي هو جميع الاجراءات والممارسات العلمية والتزبوية التي يقوم بها مدرس مادة التربية

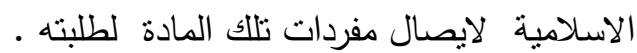

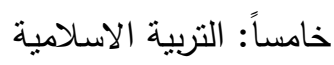

هي إعداد المسلم إعدادا كاملا من جميع النواحي في جميع مراحل نمو للحياة الدنيا والاخرة ، في ضوء

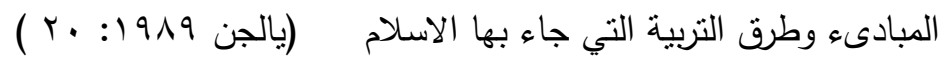

اما التعريف الاجرائي هي المواد التي نختص بتعليم العلوم الاسلامية المتمثلة في القرآن الكريم وتلاوته وحفظه وتقسيره والحديث النبوي الثريف والسيرة النبوية ، وما يرتبط بهذه العلوم ل

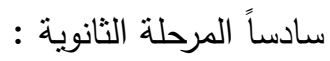

هي المرحلة الوسطى من سلم التعليم بحيث يسبقه التعليم الابتائي بحيث يسبقه التطليم الابتائي ويتلوه التعليم العالي ويشغل مدة زمنية تمند من الثانية عشرة حتى الثامنة عشرة من العمر وبذلك يتضمن التعليم التئي الثانوي المرحلتين المنوسطة والاعدادي .

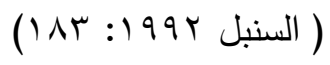

ويعرفها الباحث بانها المرحلة التي ثأتي مباشرة بعد المرحلة الابتدائية وتستمر ست سنوات مقسمة ثلاث سنوات متوسطه وثلاث سنوات اعدادي وتسبق المرحلة الجامعية. 
سيتتاول الباحث فيما يلي الدراسات التي تخدم أهداف بحثه وتقيده في إعداده ، ومن خلال إطلاع الباحث على المصادر البحث العلمي أمكنه الحصول على العديد من الدراسات منها:

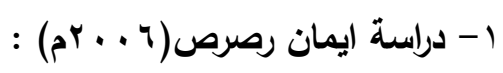

هدفت الدراسة التعرف الى درجة ممارسة معلمي التربية الاسلامية للمرحلة الإساسية في الاردن للمهارات

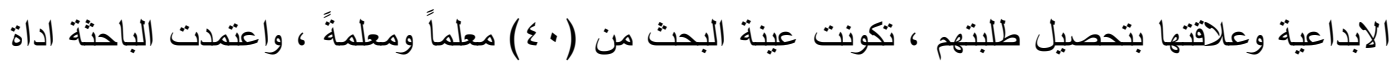

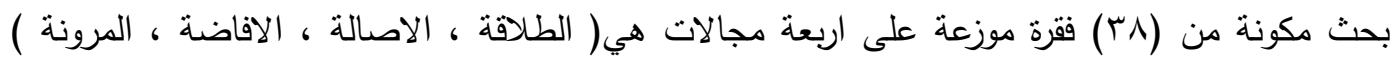

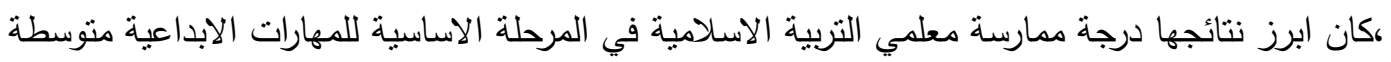

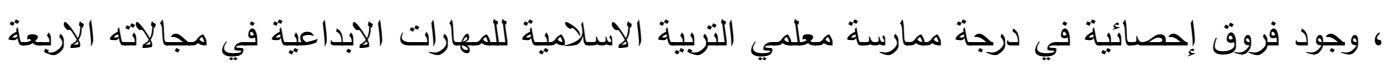

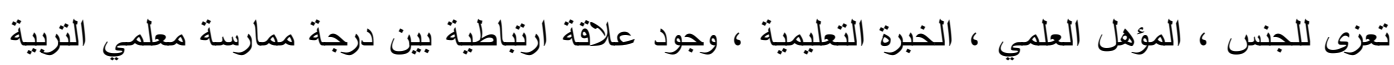

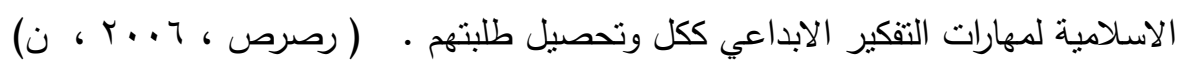

$$
\text { r- دراسة صالح عبد الكبيز (^ . . rم): }
$$

هدفت الدراسة إلى الكثف عن معوقات تعليم مهارات التفكير في مرحلة التعليم الإساسي باليمن ، بعد

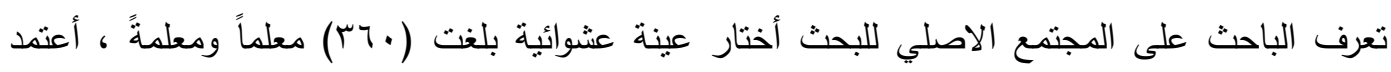

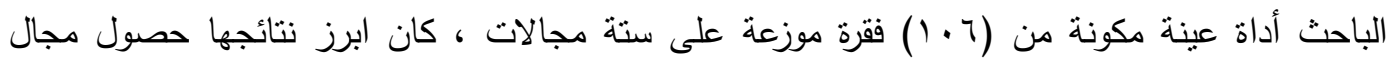

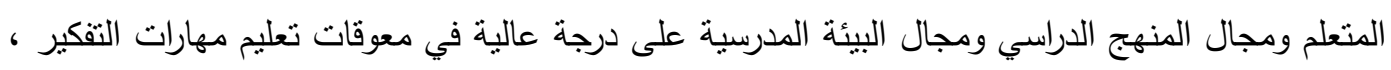

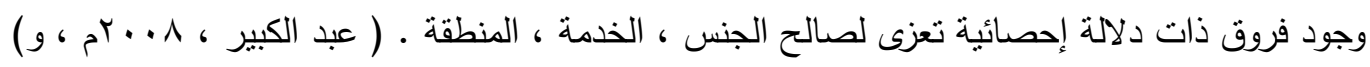

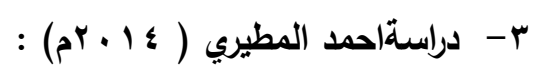

هدفت الدراسة التعرف على صعوبات تطبيق التفكير الابداعي في تدريس مادة التربية الاسلامية من وجهة

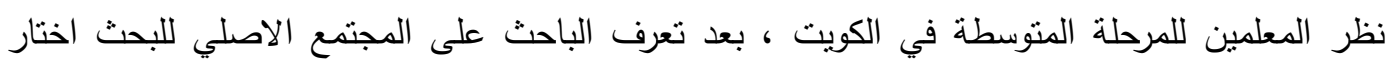

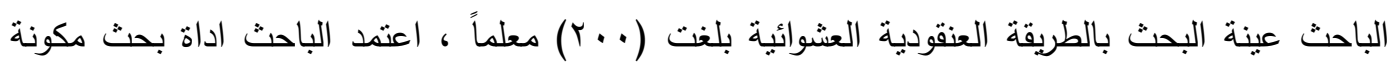




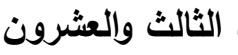

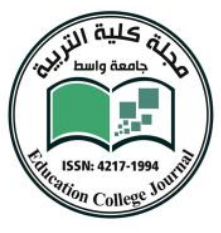

مجلـــة كليــــة التربيـــة

من(Y ) فقرة موزعة على اربعة مجالات ( التخطيط ، اهداف التدريس ، اساليب وانشطة التدريس ، تقويم التدريس ) ، كان ابرز نتائج الدراسة مستوى صعوبات تطبيق التفكير الابداعي في تدريس التربية الاسلامية مرتفعاً ، جاء في الرتبة الاولى مجال اساليب وانشطة التدريس ، وفي الرتبة الاخيرة مجال اهداف التريس ، وجود فروق ذات دلالة احصائية تعزى للصف ، للخبرة التدريسة . ( المطيري ، ع ( • ام ، م )

التعليق على الدراسات السابقة :

يتبين من خلال إطلاع الباحث على الدراسات السابقة إنها تتاولت معوقات التفكير الإبداعي في العملية التدريسة في مادة التربية الاسلامية عدا دراسة عبد الكبير حاول الكثف عن صعوبات تطبيق مهارات التفكير الابداعي بشكل عام دون تحديد مادة معينة ، ومن خلال النظر في الدراسات السابقة ذات الصلة يتبن لدى الباحث ان الدراسات السابقة تتاولت معوقات او صعوبات تطبيق مهارات التفكير الإبداعي في تدريس التربية الاسلامية للمرحلتين الاساسية والمتوسطة ، وبهذا في ضوء ما سبق لم يجد في حدود بحثه اي دراسة تتاولت معوقات تطبيق مهارات التفكير في مادة التربية الاسلامية وخصوصاً إنها اجريت في البئية العراقية وعلى مدرسي المرحلة الثانوية وهذا ما يميز البحث الحالي عن الدراسات السابقة .

الإفادة من الدراسات السابقة :

ا- ساهم إطلاع الباحث على الدراسات السابقة في تعزيز قناعة الباحث بإهمية تتاول موضوع الدراسة إذ اكدت العديد من الدراسات على ضرورة الإهنمام البحثي بهذه الموضوعات .

r- كما ساهم إطلاع الباحث على الدراسات السابقة في تحديد وصياغة مشكلة الدراسة . r-كما ساهم إطلاع الباحث على الدراسات السابقة في بناء اداة البحث. ع- كما ساهم إطلاع الباحث على الدراسات السابقة في الاطلاع على المصادر والادبيات المناسبة للبحث 
يتضمن هذا الفصل منهج البحث الذي استعمله الباحث في بحثه ويحدد مجتمع البحث وكيفية اختيار عينة

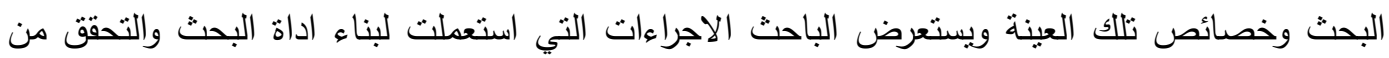
صدق تلك الاداة وثباتها وكيفية تطبيق اداة البحث ميدانيا والوسائل الاحصائية التي استخدمت في معالجة

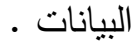

اولا منهج البحث : استعمل الباحث المنهج الوصفي الذي يعتمد على دراسة الواقع ويهتم بوصفها وصفا دقيقا ويعبر عنها تعبيرا كيفيا او تعبيرا كميا ، فالتعبير الكيفي يصف لنا الظاهرة ويوضح خصائصها ، اما التعبير الكمي فيعطينا وصفا رقميا يوضح مقدار هذه الظاهرة او حجمها ودرجات ارتباطها مع الظواهر

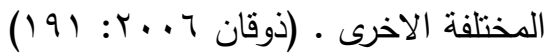
وسيتم استعمال المنهج الوصفي وفق الاتي أ-جمع البيانات من الكتب والابحاث ب-جمع البيانات من العينة

ثانيا مجتمع البحث : تمتل مجتمع البحث الحالي لجميع المدرسين الذين يعملون في الددارس (الثانوي ،الاعدادي ،المتوسط) الحكومية لاحدى المديريات الثناث في جانب الكرخ لمدينة بغداد (المديرية العامة

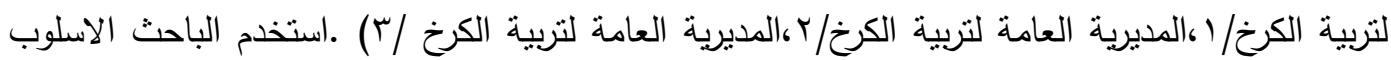

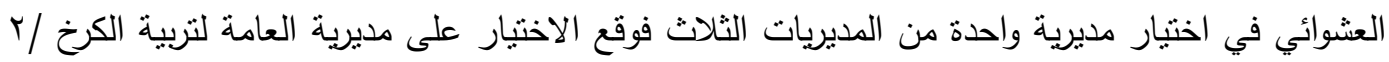

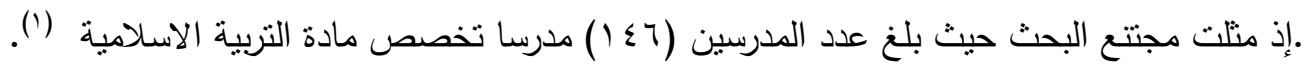

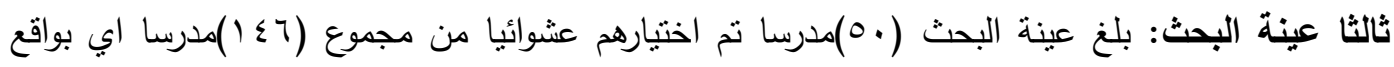

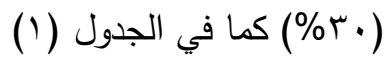


جدول (1)

\begin{tabular}{|c|c|}
\hline المدرسون & الفئة \\
\hline $1 \leqslant 7$ & مجتمع البحث \\
\hline 0 . & عينة البحث \\
\hline$\%$ \%. & النسبة \\
\hline
\end{tabular}

رابعا طريقة اختيار المدارس التي طبق فيها البحث

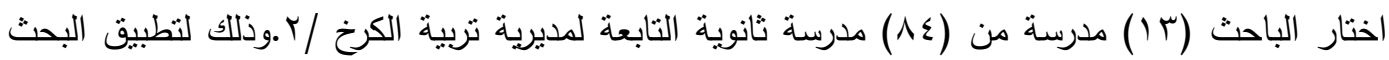
فيها وكانت طريقة اختيار تلك المدارس هي الطريقة العشوائية.

خامسا: حجم العينة : قام الباحث بتوزيع (•(م) استبانة على المدرسين في المدارس التي نم اختيارها وذللك بواقع (ع) استبانة في كل مدرسة .

سادسا عدد ماتم استرجاعه من افراد عينة البحث بعد تطبيق الاداة عليهم وماتمث معالجته فيها احصائيا : مسنمان

الاستبانات التي تم توزيعها على المدرسين والتي بلغ عددها (•0) استبانة رجع منها (IV) استبانة بفاقد

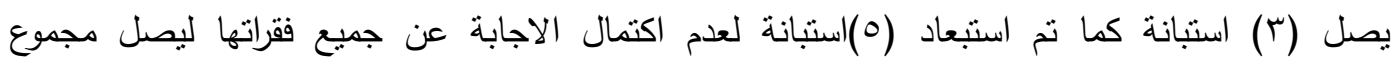

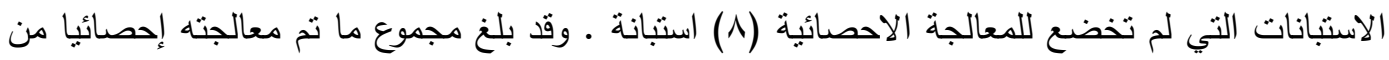

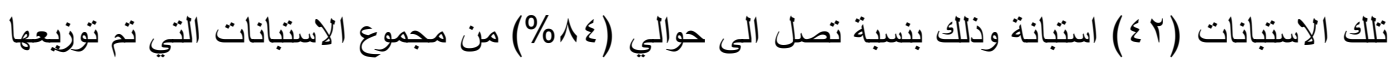

كما في الجدول (r) (r) 


\section{جدول (r)}

يوضتح عدد الاستبانات الموزعة وماتم معالجته إحصائيا منها

\begin{tabular}{|c|c|}
\hline المدرسون & البيانات \\
\hline 0. & عدد ما تم توزيعه \\
\hline$\leqslant V$ & عدد ما تم ارجاعه \\
\hline r & عدد الفاقد منها \\
\hline 0 & عدد ماتم استبعاده \\
\hline$\varepsilon r$ & عدد المتبقي الذي تم معالجته إحصائيا \\
\hline$\% \wedge \varepsilon$ & النسبة النهائية \\
\hline
\end{tabular}

سابعا اداة البحث : تم إعداد أداة البحث وهي استبانة البحث بصورتها الاولية وكتابة فقراتها لتعبر

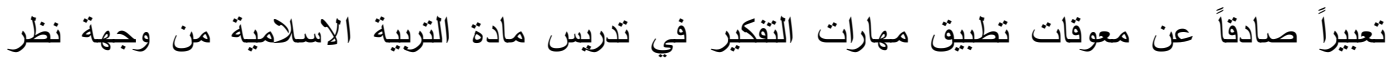

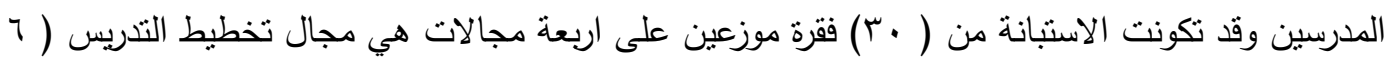

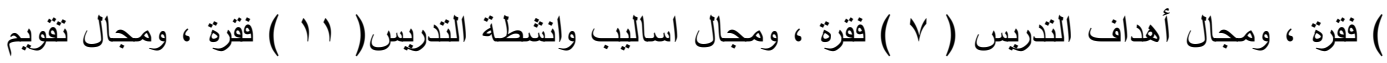

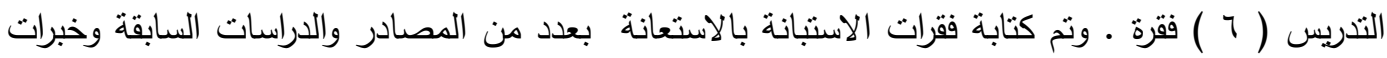
الباحثين واهتماماتهم في هذا المجال ، وتكونت إجاباتها من ثناث مستويات هي : ( موافق نماماً )

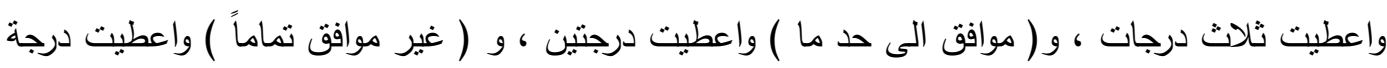
واحدة .

الصدق الظاهري للاستبانة : قام الباحث بعرض الاستبانة في صورتها الاولية على مجموعة من المحكمين

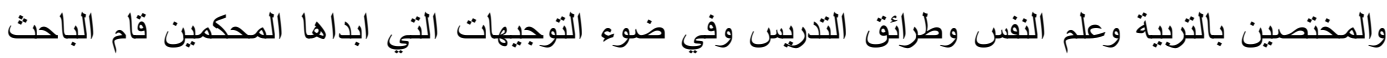
باجراء التعديلات في الصياغة اللغوية لبعض الفقرات التي اتقق عليها المحكمين على الاستبانة بنسبة

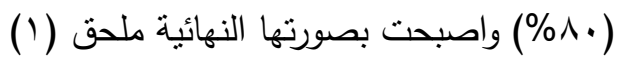

صدق الاتساق الداخلي : تم تطبيق الاستبانة على عينة استطلاعية مكونة من (•r) مدرسا لتأكد من صدق التكوين (الاتساق الداخلي للمحاور ) إذ تم حساب معامل ارتباط بيرسون بين الدرجة الكلية لكل الكل 


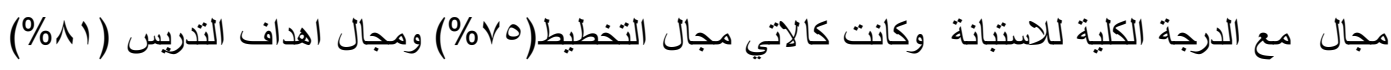

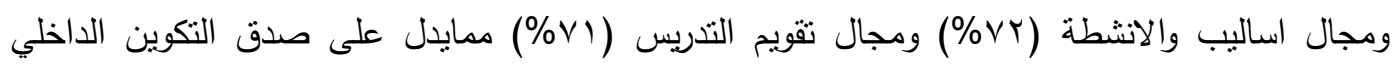

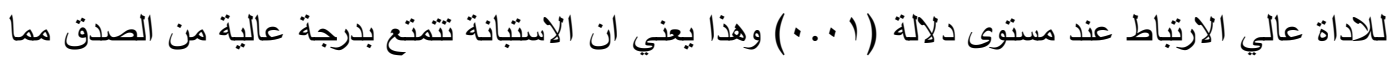

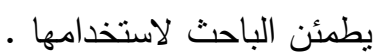

الثبات : قام الباحث بحساب ثبات الاداة على العينة الاسنطلاعية باستعمال معامل ألفا كرونباخ بطريقة

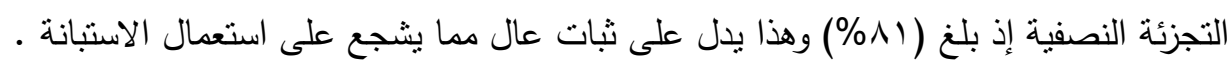

ثامنا إجراعات تطبيق اداة البحث ميدانيا : قام الباحث بتطيق اداة البحث على عينة البحث وقد

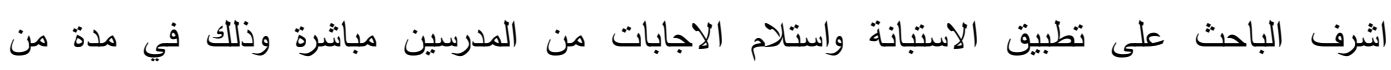

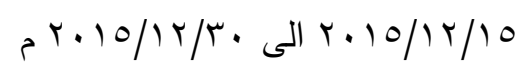

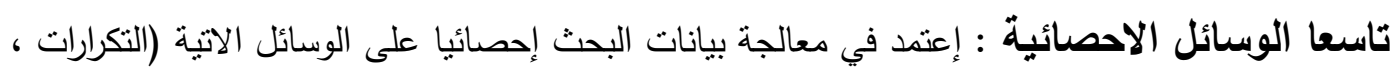

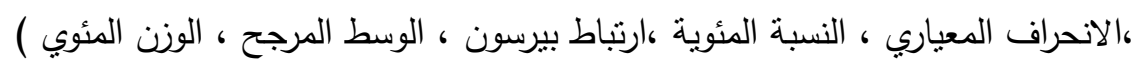


يتضمن هذا الفصل عرضاً وتفسيراً للنتائج التي نم التوصل إليها لتحقيق هدف البحث ألا وهو معوقات تطبيق مهارات التفكير في تدريس مادة التربية الاسلامية من وجهة نظر الددرسين في المرحلة الثانوية

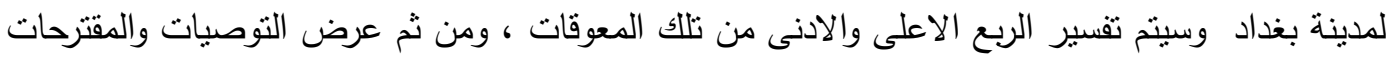

اولاً: النتائج وتقسيرها : اعتمد الباحث لعرض النتائج وتفسيرها مايأني : 1- - ترتيب المجالات وتفسيرها بشكل عام

يعرض الباحث المجالات مرتبة تتازلياً حسب حدة كل منها وسيتم تفسيرها بشكل عام كما مبين في الجدول

جدول (ץ) المجالات مرتبة تنازلياً بحسب درجة حدتها ووزنها المئوي

\begin{tabular}{|c|c|c|}
\hline الوزن المئوي & الوسط المرجح & المجالات \\
\hline AV.T. & $r .7)$ & اساليب وانثطة التندريس \\
\hline 10.74 & r.OV & تخطيط التدريس \\
\hline A...74 & T.ET & اهداف التدريس \\
\hline A. & T.\&. & تقويم التدريس \\
\hline
\end{tabular}

1- مجال اساليب وانشطة التدريس : نال هذا المجال المرتبة الاولى إذ بلغت حدته ( (T.ب) ووزن مئوي

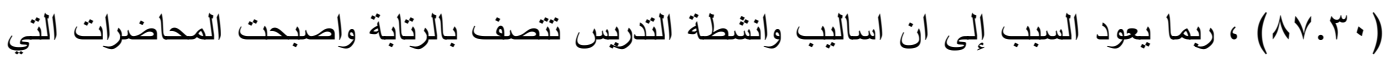

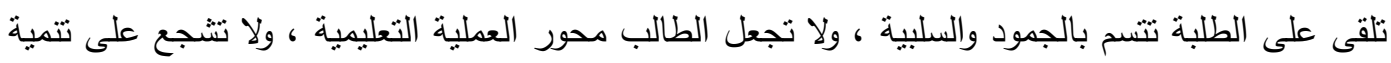

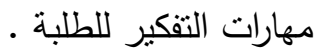

Y- مجال تخطيط للتدريس : جاء هذا المجال في المرتبة الثانية إذ بلغت حدته (Y.OV) ووزن مئوي (10.77) • والسبب في ذلك ربما عدم وجود الوقت الكافي للتخطيط التدريس الذي يساعد على تدريس و

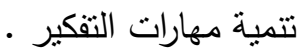


r- مجال اهداف التدريس : جاء هذا المجال في المرتية الثالثة إذ بلغت حدته (rع.r) ووزن مئوي (74. . (1) ، ربما يعود السبب عدم كفاية مدرسي التربية الاسلامية في صياغة اهداف تساعد في تدريس مهارات التفكير - ع

ع- مجال تقويم التدريس : جاء هذا المجال في المرتبة الرابعة إذ بلغت حدته (•ـ.ب) ووزن مئوي (•^) . ربما يعود السبب في ضعف اعداد مدرسي التربية الاسلامية في بناء اختبارات شاملة تتضمن اسئلة تساعد لتهد

على تتمية مهارات التقكير لدى الطلبة . r- : ترنيب المعوقات وفق مجالاتها : يعرض الباحث المعوقات مرتبة تتازلياً حسب درجة حدة كل منها وفق مجالها وسينم تفسير الربع الاعلى والربع الادنى منها . المجال الاول: تخطيط التدريس

يضم هذا المجال (T) معوقات تتعلق بمجال تخطيط التدريس كما مبين في جدول (ع)

\section{جدول (؛)}

يضم معوقات مجال تخطيط التدريس مرتبة تنازلياً بحسب التكرارات ودرجة حدتها ووزنها المئوي

\begin{tabular}{|c|c|c|c|c|c|c|c|}
\hline 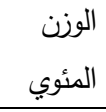 & المرجط & ك5 & كـr & كץ & 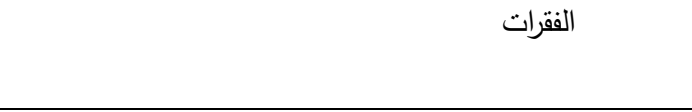 & ترتيبها & 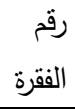 \\
\hline 10.77 & r.OV & $\varepsilon$ & 1 . & rA & تركز عمليات التخطيط للتدريس على الاساليب التقليدية & 1 & 0 \\
\hline $1 . .10$ & r.乏. & $\checkmark$ & 11 & $r \varepsilon$ & التقكير & r & 1 \\
\hline$v \varepsilon .7$ & t.rt & 1. & ir & r. & خلو التخطيط من أفكار منظمة لتدريس مهارات التفكير العامة. & r & 7 \\
\hline$\checkmark 1 . \varepsilon r$ & r.l $\varepsilon$ & 1. & r & 19 & تركيز المدرس في تخطيط التدريس على الانشطة ذات & $\varepsilon$ & r \\
\hline 77.77 & r & $1 \varepsilon$ & $1 \varepsilon$ & $1 \leq$ & خلو الانشطة المخططة لها في التدريس من مهارات التقكير & 0 & r \\
\hline $70 . . V$ & 1.90 & $1 \leq$ & 17 & it & غياب الانشطة التفكيرية عن التخطيط للتدريس & 7 & $\varepsilon$ \\
\hline
\end{tabular}


1- تركز عمليات التخطيط للتدريس على الاساليب الثقليدية

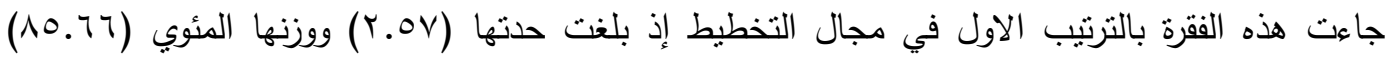
ويعود السبب الرئيس في ذللك ان تدريس هذه المهارات تحتاج إلى الوقت والجهدوالخبرة والكفاءة ، كثرة الإعباء الوظيفية والاجتماعية على المدرس تؤدي إلى عدم توفر الوقت اللازم لتخطيط تدريس وتتمية هذه

r- غياب الانشطة التفكيرية عن التخطيط للتنريس

جاءت هذه الفقرة بالترتيب الاخير في مجال التخطيط إذ بلغت حدتها(90.90) ووزنها المئوي (V. . 1.7) ، يعود السبب في ذلك إلى وجود اتجاهات وميول لادى اغلب المدرسين نحو الاستمرار في التدريس التقليدي

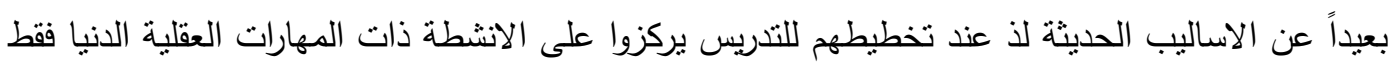

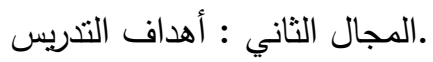

يضم هذا المجال (V) معوقات تتعلق بمجال أهداف التدريس كما مبين في جدول (0)

\section{جدول (•)}

يضم معوقات مجال اهداف التدريس مرتبة تنازلياً بحسب التكرارات ودرجة حدتها ووزنها المئوي

\begin{tabular}{|c|c|c|c|c|c|c|c|}
\hline 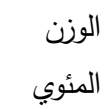 & 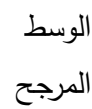 & ك5 & ك5r & كץ & الفقرات & ترتييها & 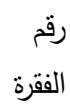 \\
\hline $1 . .74$ & $r . \varepsilon r$ & $v$ & 1. & ro & تركز التفير الدنياف تدريس التربية الاسلامية على مهارات & 1 & $1 r$ \\
\hline V7.19 & T.YA & 1. & 1. & rr & تدريسية نحفز ونتجع على التربية الاسلامية على صياغة اهداف & r & 9 \\
\hline$V \leqslant .7$. & T.KT & 1. & IT & r. & بالمشكلات التنريسية التزبية الاسلامية عن تتمية الاحساس & $r$ & $\wedge$ \\
\hline$\top \lambda$ & r... & $1 \varepsilon$ & Ir & 17 & التصنار اهداف التنريس لمادة التربية الاسلامية لمهارة & $\varepsilon$ & v \\
\hline
\end{tabular}


الثالث والعشرون

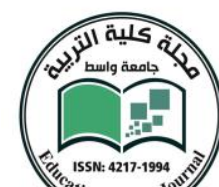

\begin{tabular}{|c|c|c|c|c|c|c|c|}
\hline דצ.ד & r & $1 \varepsilon$ & $1 \varepsilon$ & $1 \varepsilon$ & التحليل التقار التدريس لمادة التربية الاسلامية لمهارة & 0 & 1. \\
\hline $10 . . V$ & 1.90 & $1 \varepsilon$ & 17 & IT & التحلقار اهداف التكريس لمادة التربية الاسلامية المهارة & 7 & 11 \\
\hline$T \Sigma . \leqslant Y$ & $1.9 r$ & $1 \varepsilon$ & IV & 11 & الاستقار اهداف التدريس لمادة التربية الاسلامية لمهارة & V & Ir \\
\hline
\end{tabular}

مجلــــة كليــــة التربيــــة

ا - تركز اهداف تدريس التربية الاسلامية على مهارات التفكير الدنيا .

جاءت هذه الفقرة في المرنبة الاولى في مجال اهداف التثريس إذ بلغت حدتها (rع.r) ووزن مئوي( 7 ـ ، ^) ، والسبب في ذلك تركيز المناهج والكتب المدرسية على فلسفة مفادها الاهتمام بتراكم المعرفة واعتماد المدرس على الكتاب المدرسي حصراً.

r- افتقار اهداف التدريس لمادة التربية الاسلامية لمهارة الاستقراء

جاءت هذه الفقرة في المرتبة الاخيرة في مجال اهداف التدريس إذ بلغت حدتها (r9. () ووزن مئوي(Y §.ء 7) ،والسبب في ذلك يعود الى وجود معوقات تتعلق بالمنهج ، وضعف تأهيل المدرسين فيما يتعلق بتتمية التفكير لدى الطلبة وعدم توفر البيئة الصفية المدرسية الملائمة لإثارة التفكير • 
يضم هذا المجال (1') معوقة تتعلق بمجال اساليب وانشطة التدريس كما مبين في جدول (T)

\section{جدول (7)}

يضم معوقات مجال اساليب وإنثطة التدريس مرتبة تنازلياً بحسب التكرارات ودرجة حدتها ووزنها المئوي

\begin{tabular}{|c|c|c|c|c|c|c|c|}
\hline 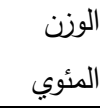 & المرجح & كا & كזr & كץ & الفقرات & ترتيبها & الفقرة \\
\hline AV.r. & r.T) & $\varepsilon$ & $\wedge$ & $r \cdot$ & بعد انثطة التدريس عن إثارة التفكير لدى الطلبة & 1 & $1 \leqslant$ \\
\hline הז.r. & T.O. & 1 & 9 & rr & خلوعملية التندريس من الاساليب المنظمة لتعلم مهارات النفكير & r & 10 \\
\hline Ar.ro & r. $\leqslant V$ & 1 & 1. & r & التركيز على حل المشكلات على الاسلوب النقليدي & r & 17 \\
\hline A. . .74 & r. $\leqslant r$ & 1 & ir & $r \varepsilon$ & الانسلاضية مستوى الاثارة والتحفيز في تدريس مادة التربية & $\varepsilon$ & 11 \\
\hline VQ.r & r.TA & $\wedge$ & 1. & $r \varepsilon$ & استهزاء المدرس بأفكار الطلبة & 。 & iv \\
\hline VT & Y.YA & $\wedge$ & $1 \varepsilon$ & r. & إجبار الطلبة على استخدام اسلوب محدد للتوصل للننائج & 1 & 19 \\
\hline vi & T.YA & 9 & ir & r) & غياب التثجيع على حب الاستطلاع لاى الطلبة & v & r \\
\hline $\mathrm{VT}$ & r.19 & 11 & ir & 19 & خلو التدريس من اسلوب العصف الذهني & $\wedge$ & r. \\
\hline$v \cdot . r T$ & r.11 & ir & ir & iv & والدرس فجوة بين الجوانب النظرية والتطيقية في التدريس لدى & q & r \\
\hline ↔ & r... & ir & 17 & $1 \varepsilon$ & الافكار الاسئلة التي تعمل على توليد اكبر قدر ممكن من & 1. & r \\
\hline 70 & 1.90 & $1 \varepsilon$ & 17 & ir & ضعف نتيع الطلبة على قبول الافكار مهما كانت غريبة & 11 & $r \leqslant$ \\
\hline
\end{tabular}


1- بعد أنشطة الترريس عن إنارة التقكير لدى الطلبة

جاءت هذه الفقرة بالمرتبة الاولى في مجال اساليب وانشطة التدريس إذ بلغت حدتها ( (T.ب) ووزن مئوي

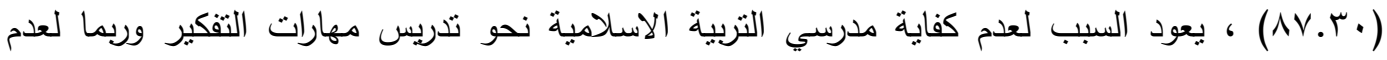

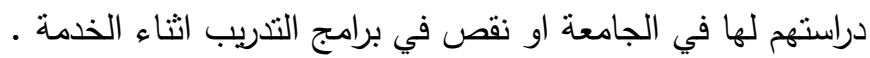
r- خلو عملية التدريس من الاساليب المنظمة لتعلم مهارات التفكير

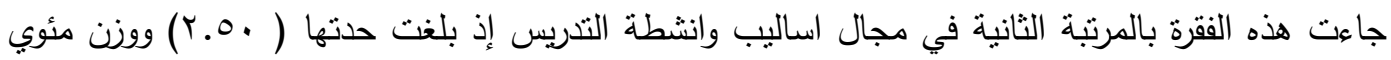
(Tr.r.) ، يعود السبب الى وجود العديد من العقبات منها نقص المعلومات حول هذه المهارات والاعتقاد

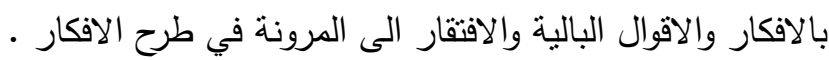
r- افتقار الاسئلة التي تعمل على توليد اكبر قدر ممكن من الافكار •

جاءت هذه الفقرة بالمرتبة العانرة في مجال اساليب وانشطة التدريس إذ بلغت حدتها ( ع ..ب) ووزن مئوي (11 ) ، يعود السبب في هذه النتيجة إلى وجود الكفاءة المعرفية لدى المدرسين حول مهارات التفكير ولكن

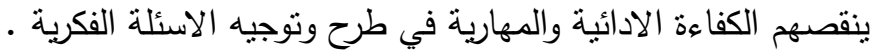
ع - ضعف تنشيع الطلبة على قبول الافكار مهما كانت غريبة .

جاءت هذه الفقرة بالمرنبة الاخيرة في مجال اساليب وانشطة التنريس إذ بلغت حدنها (90. (1) ووزن مئوي (70) كيعود السبب ربما لامر تتعلق بالطلبة انفسهم او طبيعة البيئة الصفية او الادارة الصفية المتعلقة بضبط سلوك الطلبة داخل الصف الدراسي • 
يضم هذا المجال (T) معوقات تتعلق بمجال تقويم التدريس كما مبين في جدول (V)

جدول (v)

يضم معوقات مجال تقويم التدريس مرتبة تنازلياً بحسب التكرارات ودرجة حتتها ووزنها المئوي

\begin{tabular}{|c|c|c|c|c|c|c|c|}
\hline الوزن المئوي & المرجح & كا & كى & ك5 & الفقرات & ترتيبها & رقفر \\
\hline$\wedge$. & r.\&. & $\wedge$ & ir & rr & التقويم المعتمدة على التحصيل المعرفي فقط لاساليب & 1 & ro \\
\hline V7.91 & T.T. & v & 10 & $r$. & خلو التقويم من الاسئلة الفكرية & r & ru \\
\hline$v \varepsilon .7$. & T.KT & 9 & $1 \varepsilon$ & 19 & تركيز الثقويم في مادة التربية الاسلامية على الديار & r & ד \\
\hline VT.A. & T.r. & 9 & 10 & 11 & للامتحان المدرسي التربية الاسلامية باجتياز الطلبة & $\varepsilon$ & rr \\
\hline VI.rT & r.I & 1. & 17 & 17 & انشغال الطلبة بتقويم افكارهم قبل طرحها & 0 & $r$ r. \\
\hline VI.rT & r. $1 \leqslant$ & 1. & 17 & 17 & ضن بين الافكار المطروحة الطلبة في اختيار افكار مناسبة & 1 & rq \\
\hline
\end{tabular}

1- استعمال مدرسي التربية الاسلامية لاساليب التقويم المعتمدة على التحصيل المعرفي فقط

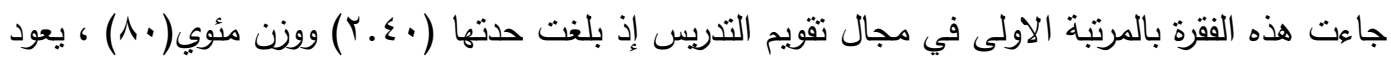

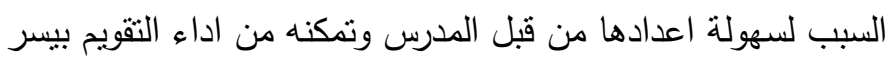

r- ضعف توجيه الطلبة في اختبار افكار مناسبة من بين الافكار المطروحة .

جاءت هذه الفقرة في الترتيب الاخير في مجال تقويم التدريس إذ بلغت حدتها (عا.ب) ووزن مئوي

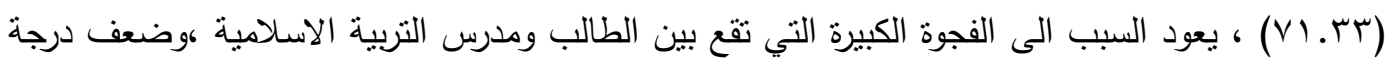
التزام الطلبة بالاداء الجدي والعملي وتدني الدافعية لتعلم التربية الاسلامية . لهعبية 
1- هناك نقص واضح في معلومات المدرسين حول مهارات التفكير الاساسية.

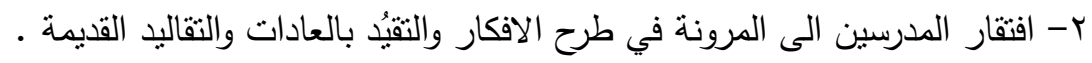
r- ميول المدرسين نحو الاستمرار في التدريس التقليدي والتلقيني بعيداً عن الاساليب الحديثة. ع - نركيز المدرسين في عمليات تخطيط التدريس على الاساليب التقليدية . ه- خلو تخطيط التدريس من الانشطة الدحفزة على مهارات التفكير الاساسية . 1- اهداف التدريس لمادة التربية الاسلامية للمرحلة الثانوية تخلو من بعض مهارات التفكير الاساسية ومنها

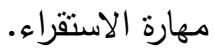

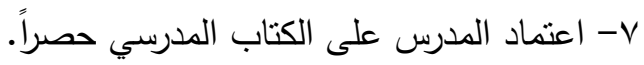
ثانياً: التوصيات : يوصي الباحث بماياتي :

1- الإفادة من المؤشرات التي اسفر عنها البحث لغرض الارتقاء بالمستوى العلمي للعملية التعليمية

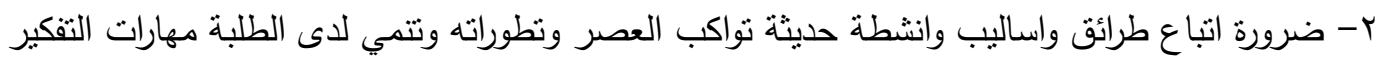
r- ضرورة الاهتمام في الاهداف التدريسة وخصوصاً تلك تساعد على تتمية مهارات التفكير لدى الطلبة . ثالثاً : المقترحات : يقتزح الباحث ماياتي :

ا - اجراء دراسة مماتلة للدراسة الحالية من وجهة نظر المدرسات ومقارنتها بنتائج الدراسة الحالية . ץ- اجراء دراسة مماثلة للدراسة الحالية تبين صعوبات تطبيق مهارات التفكير الناقد في تدريس التربية

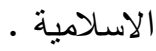
r- اجراء دراسة نبين معوقات تطبيق مهارات التفكير في تدريس مادة التلاوة في الجامعات. 


$$
\text { المصادر }
$$

القرآن الكريم

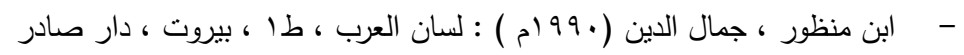

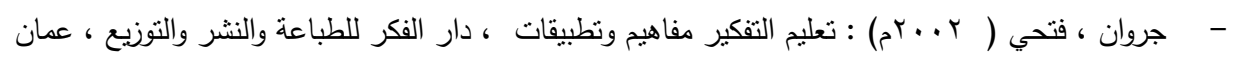

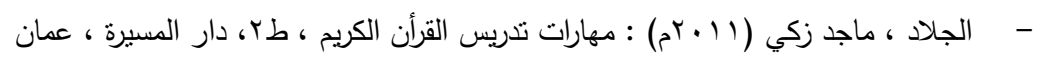

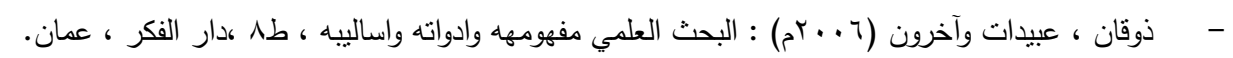

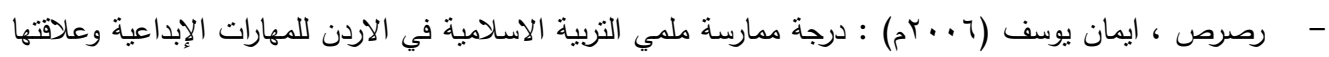

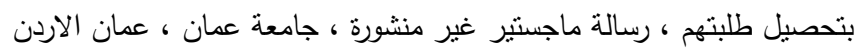

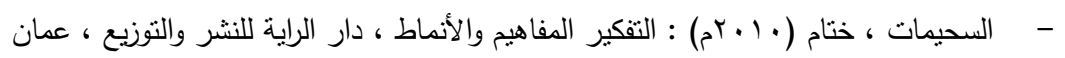

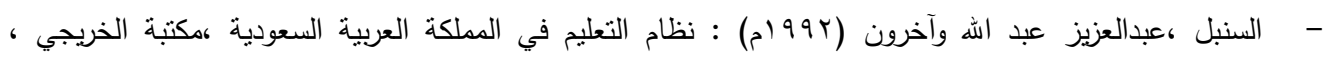
الرياض

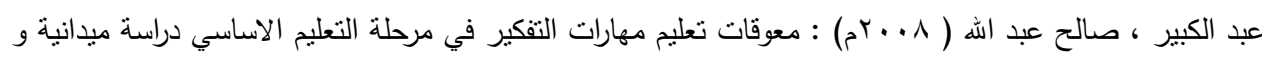

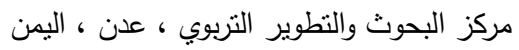

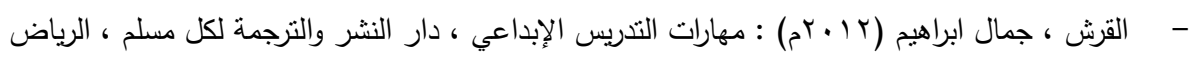

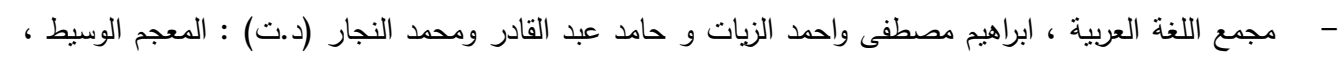
دار الدعوة ، القاهرة

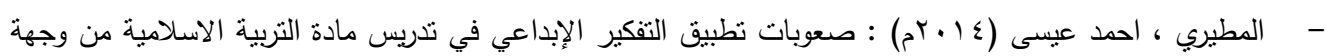

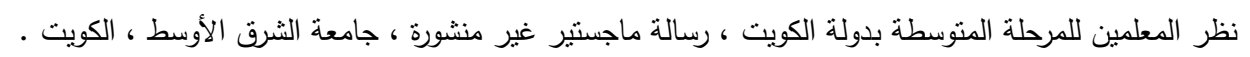

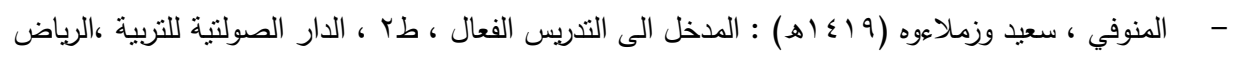

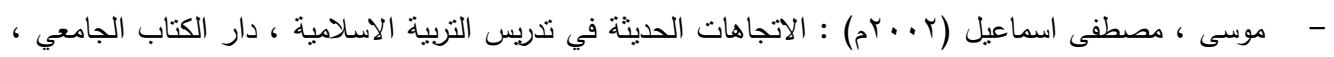
العين - يالجن ، مقداد (.99 1م) : اهداف التربية الاسلامية وغاياتها ، طب ،دار الهدى للنشر والتوزيع ، الرياض. 


\section{مجلـــة كليــــة التربيـــة}

ملحق (1)

استبانة معوقات تطبيق مهارات التفكير بصيغتها النهائية

\begin{tabular}{|c|c|c|c|c|}
\hline نمافاً & 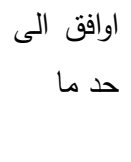 & 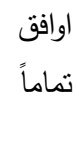 & الفقرة / اولاً مجال تخطيط التنريس & $ت$ \\
\hline & & & ابتعاد تخطيط التنريس عن الانثطة المحفزة على مهارات التفكير & 1 \\
\hline & & & تركيز الددرس في تخطيط التنريس على الانثطة ذات المهارات العقلية & r \\
\hline & & & خلو الانشطة المخططة لها في التنريس من مهارات التفكير & r \\
\hline & & & غياب الانثطة التفكيرية عن التخطيط للتدريس & $\varepsilon$ \\
\hline & & & تركز عمليات التخطيط للنتريس على الاساليب التقليدية & o \\
\hline & & & خلو التخطيط من أفكار منظمة لتتريس مهارات التفكير العامة. & 1 \\
\hline & & & الفقرة/ ثانياً مجال اهداف التندريس & \\
\hline & & & افتتار اهداف التتريس لمادة التربية الاسلامية لمهارة التصنيف & $\mathrm{v}$ \\
\hline & & & بعد اهداف التربية الاسلامية عن تتمية الاحساس بالمشكلات التدريسية & $\wedge$ \\
\hline & & & ونشجع على التفكير التربية الاسلامية على صياغة اهداف تدريسية تحفز & 9 \\
\hline & & & افتقار اهداف التدريس لمادة التربية الاسلامية لههارة التحليل & 1. \\
\hline & & & افتثقار اهداف التتريس لمادة التربية الاسلامية المهارة التحليل & 11 \\
\hline & & & افتقار اهداف التتريس لمادة التربية الاسلامية لمهارة الاستقراء & ir \\
\hline & & & تركز اهداف تدريس التربية الاسلامية على مهارات التفكير الدنيا & ir \\
\hline & & & الفقرة/ ثالثاً مجال اساليب وانثطة التنريس & \\
\hline & & & بعد انشطة التدريس عن إثارة التفكير للى الطلبة & $1 \leqslant$ \\
\hline & & & خلوعلية التنريس من الاساليب المنظمة لتعلم مهارات التفكير & 10 \\
\hline & & & التركيز على حل المشكلات على الاسلوب النقليدي & 17 \\
\hline & & & استهزاء المدرس بأفكار الطلبة & iv \\
\hline & & & انخفاض مستوى الاثارة والتحفيز في تدريس مادة التزبية الاسلامية & 11 \\
\hline & & & إجبار الطلبة على استخدام اسلوب محدد للنوصل للنتائج & 19 \\
\hline & & & خلو التريس من اسلوب العصف الذهني & r. \\
\hline
\end{tabular}




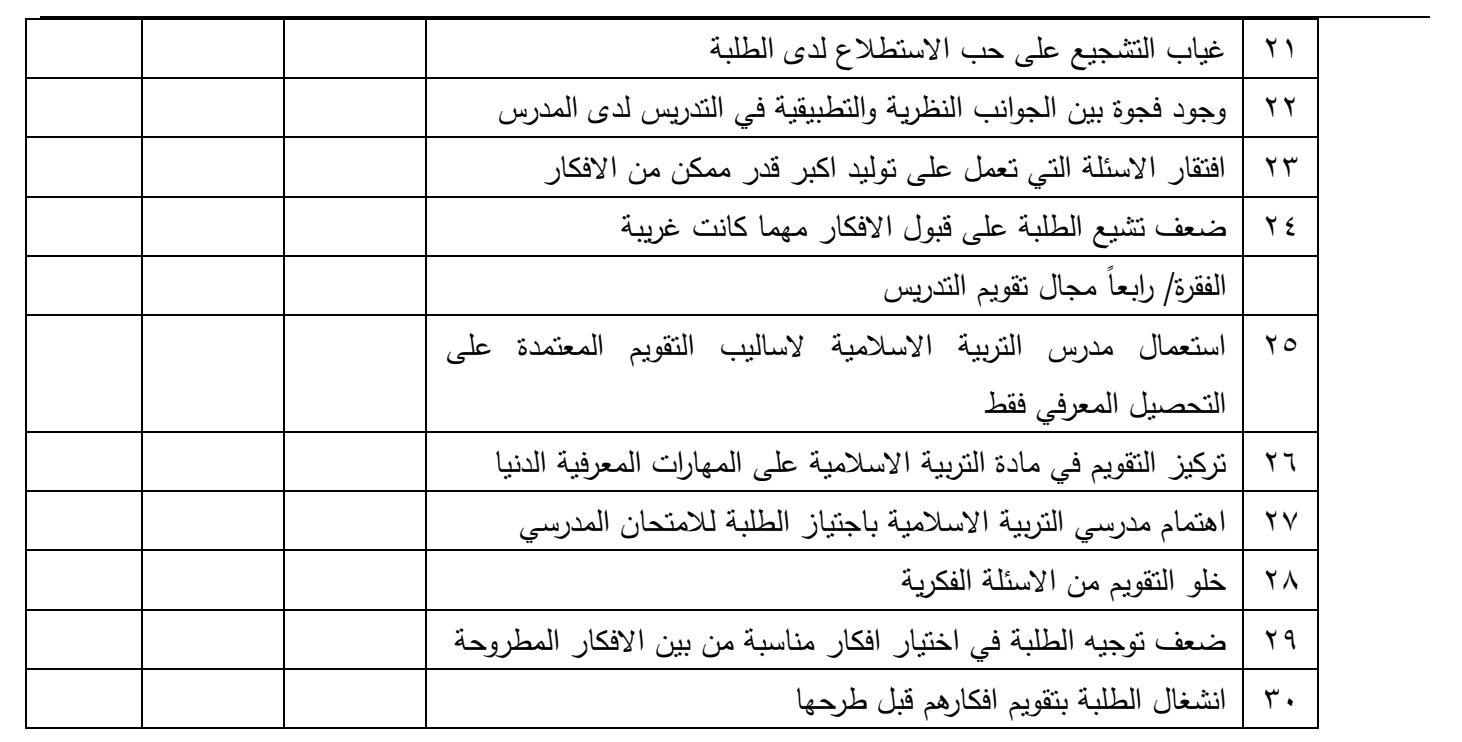

\section{مجلـــة كليـــة التربيـــة}

الهوامش

' - حصل الباحث على اعداد المدرسين من دائرة التخطيط والاحصاء التربوي في وزارة التربية 